\title{
PERAN PEMEDIASIAN MOTIVASI TERHADAP PENGARUH KARAKTERISTIK INTI PEKERJAAN DAN EFIKASI DIRI PADA KEPUASAN KERJA PEBISNIS ONLINE DI KOTA JAMBI
}

\author{
Nur Hasanah ${ }^{1)}$, Novita Ekasari ${ }^{2)}$ \\ ${ }^{1,2)}$ Prodi Manajemen Fakultas Ekonomi dan Bisnis Universitas Jambi \\ Email : nur_hasanah@unja.ac.id, ekasari.novita01@yahoo.com
}

\begin{abstract}
This study proposes a mechanism to explain the effect of core job characteristics and selfefficacy on job satisfaction of online businesses in the city of Jambi. Previous research indicates that there are motivational factors that contribute to explaining the mechanism. This study aims to examine the effect of core job characteristics and self-efficacy positively and directly on job satisfaction. In addition, this study also aims to examine the effects of motivation mediation on the influence of core job characteristics and self-efficacy on job satisfaction. The study was conducted by survey method, with the research instrument in the form of an online questionnaire. A sample of 100 online business people in the city of Jambi. The data collection method is carried out by distributing questionnaires to respondents who are online businesses with various types of business. The unit of analysis in this study is the individual. The method of data analysis uses Structural Equation Modeling (SEM) with the help of AMOS 22.0 software. The results showed that motivation partially mediates the effect of core job characteristics and self-efficacy on job satisfaction of online businesses in the city of Jambi.
\end{abstract}

Key words: Core Job Characteristics, Self Efficacy, Motivation, Job Satisfaction

\section{PENDAHULUAN}

Potensi industri e-commerce di Indonesia memang tidak dapat dipandang sebelah mata. Dari data analisis Ernst \& Young, dapat dilihat pertumbuhan nilai penjualan bisnis online di tanah air setiap tahun meningkat 40 persen. Perilaku konsumtif dari puluhan juta orang kelas menengah di Indonesia menjadi alasan mengapa e-commerce di Indonesia akan terus berkembang. Pada tahun 2020, volume bisnis e-commerce di Indonesia diprediksi akan mencapai USD 130 miliar dengan angka pertumbuhan per tahun sekitar 50 persen. Pemerintah Indonesia ingin menempatkan Indonesia sebagai Negara Digital Economy terbesar di Asia Tenggara pada tahun 2020. Selain adanya E-commerce Roadmap, pemerintah menargetkan dapat menciptakan 1.000 technopreneurs baru pada tahun 2020 dengan valuasi bisnis USD 10 miliar. Dengan pertumbuhan bisnis online yang begitu pesat, masyarakat Indonesia akan mendapatkan manfaat positif dalam perekonomian seperti pertumbuhan kesejahteraan, pertumbuhan lapangan kerja baru dan lain-lain. Dengan demikian Indonesia tidak lagi sekadar menjadi target pasar bisnis internasional, tetapi sebaliknya dapat menjadi pengusaha e-commerce yang mumpuni hingga menjangkau pasar luar negeri (Kementerian Komunikasi dan Informatika, 2015).

Para pengusaha e-commerce ini lebih dikenal dengan sebutan para pebisnis online. Mereka adalah para pebisnis/pengusaha yang menggunakan alat elektronik yang menggunakan bantuan teknologi informasi dan komunikasi untuk memasarkan produk berupa barang atau jasa. Bisnis online ini banyak diminati masyarakat karena selain cukup mudah dilakukan, bisnis ini bisa dimulai dengan modal yang kecil namun menjanjikan keuntungan yang lumayan besar bagi pelakunya. Peneliti tertarik untuk mengetahui apa 
saja faktor penyebab semakin meningkatnya pertumbuhan dan perkembangan bisnis online saat ini. Banyak pelaku yang sudah berkecimpung lama di dunia bisnis online. Hal ini mengindikasikan bahwa para pelaku bisnis online ini puas dengan pekerjaannya, karena jika mereka tidak puas dengan pekerjaannya, bagaimana mungkin mereka terus bertahan di dalamnya dan bahkan mengajak orang-orang terdekat mereka untuk ikut bergabung dalam dunia bisnis online sehingga terjadi peningkatan jumlah pebisnis online. Kepuasan kerja bisa disebabkan oleh banyak faktor. Robbins \& Judge (2016) mengatakan bahwa motivasi dapat meningkatkan kepuasan kerja. Begitu pula dengan karakteristik inti pekerjaan dan efikasi diri juga dapat meningkatkan motivasi dan kepuasan kerja.

Didasarkan pada latar belakang di atas, maka pertanyaan penelitian ini adalah: (1) Apakah karakteristik inti pekerjaan berpengaruh positif dan langsung pada kepuasan kerja pebisnis online di Kota Jambi? (2) Apakah efikasi diri berpengaruh positif dan langsung pada kepuasan kerja pebisnis online di Kota Jambi? (3) Apakah motivasi memediasi pengaruh karakteristik inti pekerjaan dan efikasi diri pada kepuasan kerja pebisnis online di Kota Jambi?

Hackman dan Oldham (1976) dalam Piccolo dan Colquitt (2006) memperkenalkan teori karakteristik pekerjaan untuk menjelaskan kondisi karyawan yang termotivasi secara intrinsik ketika melakukan suatu pekerjaan. Menurut teori ini, organisasi dapat mendukung sikap kerja positif dan kualitas kerja yang meningkat dengan mengembangkan karakteristik pekerjaan di sepanjang lima dimensi. Dimensi-dimensi ini meliputi variety (tingkat sebuah pekerjaan membutuhkan penggunaan sejumlah keahlian dan bakat yang berbeda); identity (tingkat pekerjaan membutuhkan penyelesaian dari semua bagian kerja, atau mengerjakan sebuah tugas dari awal hingga akhir dengan suatu hasil yang dapat dilihat); significance (tingkat pekerjaan memiliki suatu pengaruh substansial pada kehidupan orang lain); autonomy (tingkat pekerjaan memberikan kebebasan substansial); dan feedback (tingkat pekerjaan memberikan informasi yang jelas tentang tingkat kinerja). Penelitian terdahulu menunjukkan bahwa karakteristik inti pekerjaan berpengaruh positif dan langsung pada kepuasan kerja (Subyantoro, 2011).

Efikasi diri didefinisikan sebagai keyakinan seseorang tentang kapabilitasnya untuk menghasilkan tingkat kinerja tertentu lalu menggunakan pengaruhnya atas peristiwa yang mempengaruhi hidupnya (Bandura, 1998). Dengan kata lain, efikasi diri merupakan keyakinan diri individu bahwa dia mampu atau tidak mampu melakukan suatu tindakan untuk mencapai hasil tertentu dengan berhasil (Bandura, 1986, dalam Ardiyanti, 2016). Penelitian terdahulu menunjukkan bahwa efikasi diri berpengaruh positif dan langsung pada kepuasan kerja (Lodjo, 2013).

Berdasarkan uraian tersebut maka disusun hipotesis:

H1: Karakteristik Inti Pekerjaan berpengaruh positif dan langsung pada kepuasan kerja

H2: Efikasi Diri berpengaruh positif dan langsung pada kepuasan kerja

Penelitian Piccolo dan Colquitt (2006); Farh, Podsakoff, dan Organ (1990); Gellathy dan Irving (2001); Bell dan Menguc (2002); Podsakoff dan MacKenzie (1995); Podsakoff et al., (1996a); Podsakoff et al., (1996b); Yukl dan Van Fleet (1982); Bass (1985); dan Shamir et al. (1993) dalam Purvanova et al. (2006) mengungkapkan bahwa, persepsi karyawan terhadap karakteristik inti pekerjaan mempengaruhi perilaku kerjanya. Pekerjaan yang memberikan otonomi kerja yang tinggi memberikan keleluasaan bagi karyawan dalam menyelesaikan pekerjaan sehingga akan meningkatkan motivasi karyawan secara intrinsik. Penelitian terdahulu menunjukkan bahwa karakteristik inti pekerjaan berpengaruh positif dan langsung pada motivasi (Subyantoro, 2011)

Efikasi diri menentukan bagaimana orang merasa, berpikir dan memotivasi diri mereka sendiri dan perilakunya. Keyakinan seperti ini menghasilkan efek yang berbeda 
melalui empat proses utama yaitu kognitif, motivasional, afektif dan proses seleksi (Bandura, 1998). Bandura (1997) dalam Saragih (2007) menyatakan bahwa, keyakinan tersebut akan berdampak pada usaha yang dikeluarkan untuk mencapai hasil terbaik dan pada akhirnya berdampak pada peningkatan kinerja yang semakin membaik. Penelitian terdahulu menunjukkan bahwa efikasi diri berpengaruh positif dan langsung pada motivasi (Latifah, 2018). Penelitian terdahulu juga menunjukkan bahwa motivasi berpengaruh positif dan langsung terhadap kepuasan kerja (Juniari et al, 2015; Kurnia et al, 2015).

Menurut model karakteristik pekerjaan Hackman dan Oldham (1980) dalam Boonzaier, Ficker, dan Rust (2001), karyawan menunjukkan outcome personal dan pekerjaan yang positif (seperti motivasi kerja internal, kepuasan kerja secara umum, kepuasan pertumbuhan, dan keefektifan kerja) jika mereka mengalami tiga kondisi psikologis, yaitu kebermaknaan yang dialami (experienced meaningfulness), tanggung jawab yang dialami (experienced responsibility), dan pengetahuan hasil (knowledge of results). Penelitian terdahulu menunjukkan bahwa motivasi memediasi pengaruh karakteristik inti pekerjaan pada kepuasan kerja (Subyantoro, 2009). Penelitian terdahulu juga menunjukkan bahwa motivasi memediasi pengaruh efikasi diri pada kepuasan kerja (Narendra, 2017).

Berdasarkan uraian tersebut, maka disusunlah hipotesis:

H3a: Motivasi memediasi pengaruh karakteristik inti pekerjaan pada kepuasan kerja H3b: Motivasi memediasi pengaruh efikasi diri pada kepuasan kerja

Untuk memberikan gambaran lengkap mengenai penelitian ini, maka akan disajikan sebuah gambar model penelitian. Adapun model penelitian dan hipotesisnya ini secara lebih jelas disajikan dalam gambar 2.1.

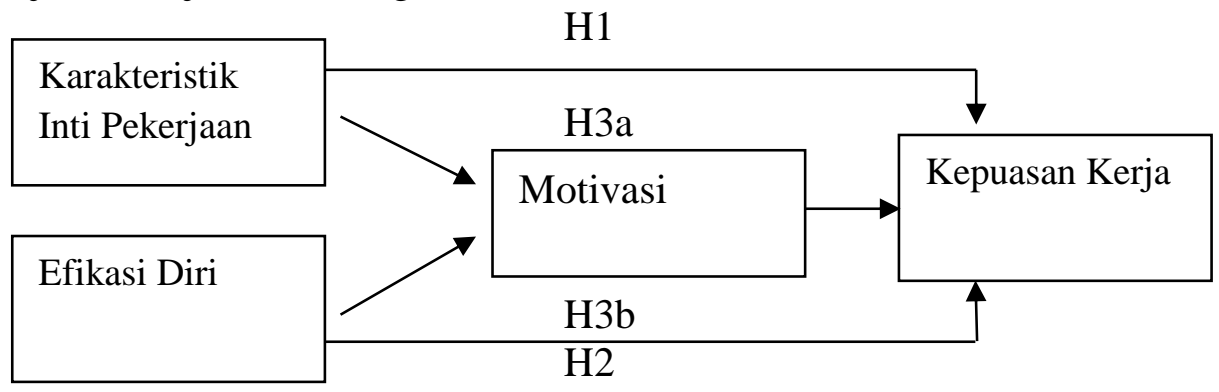

Gambar 1.

Model Penelitian

\section{METODE}

Penelitian ini menggunakan metode survei melalui penyebaran kuesioner. Responden dalam penelitian ini adalah pebisnis online di Kota Jambi dengan jenis bidang usaha yang beragam agar hasil penelitian ini memiliki validitas eksternal yang tinggi atau dapat digeneralisasi pada berbagai macam jenis atau tipe pekerjaan/usaha. Pengambilan sampel dalam penelitian ini didasarkan pada teknik convenience sampling, untuk memudahkan peneliti untuk mengumpulkan data dengan lebih cepat (Neuman, 2006). Hair et al. (2006) menyatakan bahwa ukuran sampel minimum yang direkomendasikan adalah 100-150 agar dapat menjamin solusi Maximum Likelihood Estimation (MLE) yang stabil. Oleh karena itu, jumlah sampel yang digunakan dalam penelitian ini adalah sebanyak 100 sampel. Unit analisis dalam penelitian ini adalah individual. Data yang diperlukan dalam penelitian ini dikumpulkan dengan metode survei, dengan cara memberikan kuesioner online kepada responden. 
Dalam penelitian ini terdapat empat variabel yang terdiri dari: dua variabel independen yaitu Karakteristik Inti Pekerjaan dan Efikasi Diri, satu variabel dependen yaitu Kepuasan Kerja, dan satu variabel pemediasi yaitu Motivasi. Berikut ini diringkaskan definisi operasional dan pengukuran masing-masing variabel dalam penelitian ini.

Tabel 1.

Operasional Variabel Penelitian

\begin{tabular}{|c|c|c|c|c|c|}
\hline Variabel & Dimensi & Definisi Variabel & $\begin{array}{l}\text { Sumber } \\
\text { Pengukuran }\end{array}$ & $\begin{array}{l}\text { Jumlah } \\
\text { Item }\end{array}$ & $\begin{array}{l}\text { Skala } \\
\text { Pengukuran }\end{array}$ \\
\hline $\begin{array}{l}\text { Karakteristik Inti } \\
\text { Pekerjaan }\end{array}$ & $\begin{array}{l}\text { Skill Variety } \\
\text { Task Identity } \\
\text { Task } \\
\text { Significance } \\
\text { Autonomy } \\
\text { Feedback }\end{array}$ & $\begin{array}{l}\text { Karakteristik inti } \\
\text { pekerjaan meliputi } \\
\text { skill variety, task } \\
\text { identity, } \\
\text { significance, } \\
\begin{array}{l}\text { autonomy dask } \\
\text { feedback (Hackman } \\
\text { dan Oldham, 1981) }\end{array}\end{array}$ & $\begin{array}{lr}\text { Formulir Job } \\
\text { Diagnostic } \\
\text { Survey yang } \\
\text { direvisi (Idaszak } \\
\& \quad \text { Drasgow, } \\
\text { 1987; lihat } \\
\text { Boonzaier, } \\
\text { Ficker, \& Rust, } \\
\text { 2001) }\end{array}$ & $\begin{array}{l}2 \\
2 \\
2\end{array}$ & $\begin{array}{l}1-7 \\
1=\text { "sangat tidak } \\
\text { akurat" } \\
2=\text { "tidak } \\
\text { akurat" } \\
3=\text { "agak tidak } \\
\text { akurat" } \\
4=\text { "netral" "agak } \\
5==\quad \text { "akut" } \\
\text { akurat" } \\
6=\text { "akurat" } \\
7=\text { "sangat } \\
\text { akurat" }\end{array}$ \\
\hline Efikasi Diri & $\begin{array}{l}\text { Generality } \\
\text { Strength } \\
\text { Level }\end{array}$ & $\begin{array}{l}\text { Efikasi diri } \\
\text { didefinisikan } \\
\text { sebagai keyakinan } \\
\text { seseorang tentang } \\
\text { kapabilitasnya untuk } \\
\text { menghasilkan } \\
\text { tingkat kinerja } \\
\text { tertentu lalu } \\
\text { menggunakan } \\
\text { pengaruhnya atas } \\
\text { peristiwa yang } \\
\text { mempengaruhi } \\
\text { hidupnya (Bandura, } \\
\text { 1998) }\end{array}$ & $\begin{array}{l}\text { GSE (Schwarzer } \\
\& \quad \text { Jerusalem, } \\
1995)\end{array}$ & 10 & $\begin{array}{l}1-4 \\
1=\text { "sangat tidak } \\
\text { benar" } \\
2=\text { "tidak benar" } \\
3=\text { "benar" } \\
4=\text { "sangat } \\
\text { benar", }\end{array}$ \\
\hline Motivasi & $\begin{array}{l}\text { Amotivation } \\
\text { Extrinsic } \\
\text { regulation- } \\
\text { social } \\
\text { Extrinsic } \\
\text { regulation- } \\
\text { material } \\
\text { Introjected } \\
\text { regulation } \\
\text { Identified } \\
\text { regulation } \\
\text { Intrinsic } \\
\text { motivation }\end{array}$ & $\begin{array}{l}\text { Motivasi kerja } \\
\text { merupakan } \\
\text { pemfungsian } \\
\text { optimal individu } \\
\text { (Gagne et al., 2014) }\end{array}$ & $\begin{array}{l}\text { MWMS (Gagne } \\
\text { et al., 2014) }\end{array}$ & 19 & $\begin{array}{l}1-7 \\
1=\text { "tidak sama } \\
\text { sekali" } \\
2= \\
\text { sedikit" "sangat } \\
=\text { "sedikit" } \\
=\text { "sedang" } \\
=\text { "kuat" } \\
=\text { "sangat kuat" } \\
=\text { "benar-benar } \\
\text { kuat" }\end{array}$ \\
\hline Kepuasan Kerja & $\begin{array}{l}\text { Pay } \\
\text { Promotion } \\
\text { Supervision } \\
\text { Fringe benefits } \\
\text { Contingent } \\
\text { rewards } \\
\text { Operating }\end{array}$ & $\begin{array}{l}\text { Kepuasan kerja } \\
\text { adalah perasaan } \\
\text { orang mengenai } \\
\text { pekerjaannya dan } \\
\text { beberapa aspek dari } \\
\text { pekerjaannya } \\
\text { (Spector, 1997). }\end{array}$ & $\begin{array}{l}\text { JSS } \\
\text { (Spector, 1985) }\end{array}$ & 36 & $\begin{array}{l}1-6 \\
1=\text { "sangat tidak } \\
\text { setuju" } \\
2=\text { "tidak } \\
\text { setuju" } \\
3=\text { "sedikit tidak } \\
\text { setuju" }\end{array}$ \\
\hline
\end{tabular}


conditions

Coworkers

Nature of work

Communication
$=$ "sedikit setuju"

="setuju"

$6=$ "sangat

setuju"

Metode analisis yang digunakan adalah Strutural Equation Modelling (SEM). Untuk pengujian model pengukuran (measurement model) dalam penelitian ini, dilakukan uji validitas dan reliabilitas konstruk dengan Confirmatory Factor Analysis (CFA). Untuk pengujian model struktural (structural model), mengikuti kriteria goodness of fit menurut Hair et al. (2006).

\section{HASIL DAN PEMBAHASAN}

Adapun karakteristik responden menunjukkan bahwa pebisnis online dalam penelitian ini lebih banyak terdiri dari wanita, dengan rentang usia 25-50 tahun, pendidikan sarjana, dan rentang masa kerja 1-5 tahun. Kuesioner terdiri dari 75 item pertanyaan yang mewakili setiap variabel dengan jumlah responden 100 orang dengan menggunakan aplikasi AMOS versi 22.0. Hasil yang diperoleh dari pengujian validitas dan reliabilitas CFA menunjukkan bahwa instrumen penelitian valid dan reliabel, karena sesuai dengan rule of thumb yang digunakan dalam penelitian ini adalah factor loading sebesar 0.45 atau lebih (Hair et al., 2006) dan nilai Cronbach's Alpha sebesar 0.7 atau lebih (Hair et al., 2006).

Sebelum melakukan pengujian model pengukuran dan model struktural, ada beberapa hal yang harus diperhatikan, antara lain pemeriksaan kelayakan sampel dalam SEM dengan teknik Maximum Likelihood Estimation (MLE), uji normalitas, dan pemeriksaan outliers. Penelitian ini menggunakan sampel sebanyak 100 responden. Hair et al. (2006) menyatakan bahwa ukuran sampel minimum yang direkomendasikan adalah 100-150 agar dapat menjamin solusi Maximum Likelihood Estimation (MLE) yang stabil. Oleh karena itu, jumlah sampel yang digunakan dalam penelitian ini sudah layak.

Uji Normalitas dilakukan dengan menggunkan $\mathrm{z}$ value (critical ratio atau C.R pada output AMOS 22.0) dari nilai skewness dan kurtosis sebaran data. Nilai kritis sebesar \pm 2,58 pada tingkat signifikan 0,01 (Ghozali, 2014). Berdasarkan hasil uji normalitas secara univariate mayoritas berdistribusi normal karena nilai critical ratio (c.r) untuk kurtosis (keruncingan) maupun skewness (kemencengan), berada dalam rentang -2,58 sampai $+2,58$. Sedangkan secara multivariate data memenuhi asumsi normal karena nilai 0,140 berada di dalam rentang $\pm 2,58$.

Evaluasi terhadap multivariate outliers dapat dilihat melalui output AMOS Mahalanobis Distance. Kriteria yang digunakan pada tingkat $\mathrm{p}<0.001$. Jarak tersebut dievaluasi dengan menggunakan $\mathrm{X}^{2}$ pada derajat bebas sebesar jumlah variabel terukur yang digunakan dalam penelitian. Dalam kasus ini variabelnya adalah 75 , kemudian melalui program excel pada sub-menu Insert - Function - CHIINV masukkan probabilitas dan jumlah variabel terukur, dan hasilnya adalah 118,599. Artinya semua data/kasus yang lebih besar dari 118,599 merupakan outliers multivariate. Berdasarkan hasil pengujian outliers, yang menunjukan nilai dari Mahalonobis Distance, tidak terdeteksi adanya nilai yang lebih besar dari nilai 118,599. Sehingga dapat disimpulkan bahwa data tidak ada yang outliers.

Analisis SEM hanya dapat dilakukan apabila hasil identifikasi model menunjukan bahwa model termasuk dalam kategori over-identified. Identifikasi ini dilakukan dengan melihat nilai df dari model yang dibuat. Hasil output AMOS yang menunjukan nilai df model sebesar 2694. Hal ini mengindikasikan bahwa model termasuk kategori over 
confident karena memiliki nilai df positif. Oleh karena itu analisa data bisa di lanjutkan ke tahap selanjutnya. Model struktural dalam penelitian ini dapat dilihat pada Gambar 2.

Menilai goodness of fit menjadi tujuan utama dalam SEM untuk mengetahui sampai seberapa jauh model yang dihipotesiskan "Fit" atau cocok dengan sampel data. Hasil goodness of fit ditampilkan pada Tabel 2 yang menunjukkan bahwa model penelitian mendekati model good fit. Berdasarkan keseluruhan pengukuran goodness of fit diatas mengindikasi bahwa model yang diajukan dalam penelitian ini diterima.

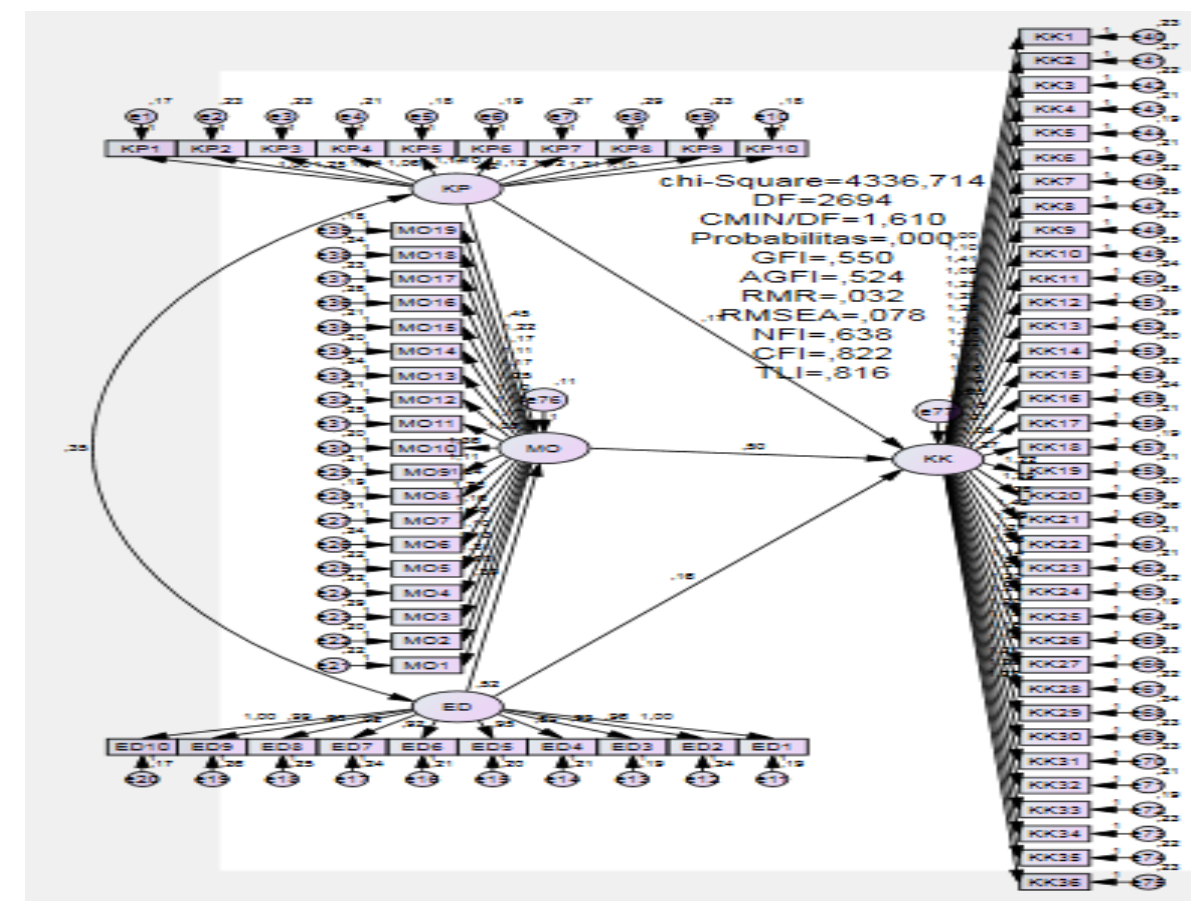

Gambar 2. Model Struktural

Tabel 2. Penilaian Goodness of Fit

\begin{tabular}{|c|c|c|c|}
\hline Goodness of fit index & Cut-off value & Model Penelitian & Model \\
\hline$\chi^{2}$ (chi-square) & $\begin{array}{l}\text { Semakin kecil semakin } \\
\text { baik }\end{array}$ & 4336,714 & Marginal \\
\hline$D F$ & $d f \geq 0$ & 2694 & Fit \\
\hline CMIN/DF & range: 3 to 1 & 1,610 & Fit \\
\hline Significant probability & $\geq 0.05$ & 0,000 & Less Fit \\
\hline GFI & $>0.90$ (range: 0 to 1$)$ & 0,550 & Marginal \\
\hline AGFI & $>0.90$ (range: 0 to 1$)$ & 0,524 & Marginal \\
\hline RMR (RMSR) & $\leq 4.0$ or $\geq-4.0$ & 0,032 & Fit \\
\hline RMSEA & $\leq 0.08$ & 0,078 & Fit \\
\hline NFI & $>0.90($ range: 0 to 1$)$ & 0,638 & Marginal \\
\hline CFI & $>0.90$ (range: 0 to 1$)$ & 0,822 & Marginal \\
\hline TLI & $>0.90($ range: 0 to 1$)$ & 0,816 & Marginal \\
\hline
\end{tabular}

Pengujian hipotesis yang dilakukan adalah untuk menjawab pertanyaan-pertanyaan pada penelitian ini atau menganalisis hubungan-hubungan model struktural. Analisis data hipotesis dapat dilihat dari nilai standardized regression weight yang menunjukkan koefisien pengaruh antar variabel dalam Tabel 3. 
Tabel 3. Pengujian Hipotesis 1 dan 2

\begin{tabular}{|c|c|c|c|c|c|c|c|}
\hline & & & Estimate & S.E. & C.R. & $\mathrm{P}$ & Hipotesis \\
\hline Kepuasan Kerja & $<---$ & $\begin{array}{l}\text { Karakteristik } \\
\text { Inti Pekerjaan }\end{array}$ & 0,170 & 0,085 & 1,986 & 0,047 & $\begin{array}{l}\text { Positif } \\
\text { Signifikan }\end{array}$ \\
\hline Kepuasan Kerja & $<---$ & Efikasi Diri & 0,155 & 0,076 & 2,047 & 0,041 & $\begin{array}{l}\text { Positif } \\
\text { Signifikan }\end{array}$ \\
\hline
\end{tabular}

Parameter estimasi nilai koefisien standardized regression weight diperoleh sebesar 0,170 dengan nilai sig. 0,047 ( $<<0,05)$, sehingga hipotesis yang menyatakan "Karakteristik Inti Pekerjaan berpengaruh positif dan langsung pada kepuasan kerja" terdukung dan dapat dinyatakan jika terdapat pengaruh secara langsung antara Karakteristik Inti Pekerjaan terhadap Kepuasan Kerja.

Parameter estimasi nilai koefisien standardized regression weight diperoleh sebesar 0,155 dengan nilai sig. $0,041(\mathrm{p}<0,05)$, sehingga hipotesis yang menyatakan "Efikasi Diri berpengaruh positif dan langsung pada kepuasan kerja" terdukung dan dapat dinyatakan jika terdapat pengaruh secara langsung antara Efikasi Diri terhadap Kepuasan Kerja.

Untuk melihat hubungan mediasi antara variable independen terhadap variable dependen melalui variable mediasi yaitu dengan cara membandingkan nilai standardized direct effect dengan standardiezed indirect effects. Artinya jika nilai standardiezd direct effects lebih kecil dari nilai standardized indierect effect maka dapat dikatakan bahwa variabel mediasi tersebut mempunyai pengaruh secara tidak langsung dalam dalam hubungan kedua variabel tersebut.

Tabel 4. Standardized Direct Effects (Group number 1-Default model)

\begin{tabular}{|c|c|c|c|c|}
\hline & Efikasi Diri & $\begin{array}{l}\text { Karakteristik } \\
\text { Inti Pekerjaan }\end{array}$ & Motivasi & $\begin{array}{l}\text { Kepuasan } \\
\text { Kerja }\end{array}$ \\
\hline Motivasi & ,447 & ,467 & ,000 &, 000 \\
\hline $\begin{array}{l}\text { Kepuasan } \\
\text { Kerja }\end{array}$ & , 197 & , 192 & ,550 & ,000 \\
\hline
\end{tabular}

Tabel 5. Standardized Indirect Effects (Group number 1-Default model)

\begin{tabular}{|c|c|c|c|c|}
\hline & Efikasi Diri & $\begin{array}{l}\text { Karakteristik } \\
\text { Inti Pekerjaan }\end{array}$ & Motivasi & $\begin{array}{l}\text { Kepuasan } \\
\text { Kerja }\end{array}$ \\
\hline Motivasi & ,000 & ,000 & ,000 &, 000 \\
\hline $\begin{array}{l}\text { Kepuasan } \\
\text { Kerja }\end{array}$ & ,246 & ,257 & ,000 &, 000 \\
\hline
\end{tabular}

Parameter estimasi untuk pengujian pengaruh karakteristik inti pekerjaan terhadap kepuasan kerja melalui motivasi diperoleh nilai direct effect < nilai indirect effect, yaitu sebesar $0,192<0,257$. Hal ini menunjukkan bahwa motivasi mampu memediasi pengaruh karakteristik inti pekerjaan terhadap kepuasan kerja, dan dapat disimpulkan bahwa hipotesis didukung.

Parameter estimasi untuk pengujian pengaruh efikasi diri terhadap kepuasan kerja melalui motivasi diperoleh nilai direct effect < nilai indirect effect, yaitu sebesar $0,197<0,246$. Hal ini menunjukkan bahwa motivasi mampu memediasi pengaruh efikasi diri terhadap kepuasan kerja, dan dapat disimpulkan bahwa hipotesis didukung.

Hasil penelitian menunjukkan bahwa motivasi memediasi pengaruh karakteristik inti pekerjaan dan efikasi diri pada kepuasan kerja pebisnis online di Kota Jambi. Hasil 
penelitian ini sejalan dengan hasil penelitian sebelumnya yang menunjukkan bahwa motivasi memediasi pengaruh karakteristik inti pekerjaan pada kepuasan kerja (Subyantoro, 2009) dan menunjukkan bahwa motivasi memediasi pengaruh efikasi diri pada kepuasan kerja (Narendra, 2017). Temuan penelitian ini mengindikasikan bahwa karakteristik inti pekerjaan dan efikasi diri dari pebisnis online akan berpengaruh positif secara efektif pada kepuasan kerjanya jika mampu membangkitkan motivasi dalam diri mereka, yang akan meningkatan kepuasan kerjanya. Karakteristik inti pekerjaan seperti skill variety, task identity, task significance, autonomy, dan feedback yang baik akan mampu meningkatkan motivasi untuk menghasilkan kepuasan kerja yang baik.

Di dalam penelitian ini mediasi yang terjadi adalah mediasi parsial. Hal ini menunjukkan bahwa meskipun motivasi memediasi pengaruh karakteristik inti pekerjaan dan dan efikasi diri terhadap kepuasan kerja, namun karakteristik inti pekerjaan dan efikasi diri ini juga masih dapat berpengaruh secara langsung pada kepuasan kerja. Pada akhirnya, hasil penelitian ini menunjukkan bahwa pengaruh karakteristik inti pekerjaan dan efikasi diri pada kepuasan kerja tidak hanya dapat terjadi secara langsung, namun juga dapat melalui perantaraan motivasi kerja.

\section{KESIMPULAN DAN SARAN}

Berdasarkan hasil penelitian, maka dapat diambil kesimpulan bahwa karakteristik inti pekerjaan dan efikasi diri berpengaruh secara positif dan langsung pada kepuasan kerja pebisnis online di Kota Jambi. Pengaruh ini juga dimediasi secara parsial oleh motivasi pebisnis online di Kota Jambi. Adapun saran yang dapat diberikan antara lain perlunya mendesain karakteristik inti pekerjaan para pebisnis online sehingga meningkatkan motivasi dan kepuasan kerjanya. Pebisnis online sebaiknya memiliki efikasi diri yang baik agar dapat senantiasa termotivasi dan puas terhadap pekerjaannya.

\section{UCAPAN TERIMAKASIH}

Ucapan terimakasih ditujukan kepada Fakultas Ekonomi dan Bisnis Universitas Jambi, khususnya Program Diploma III Ekonomi yang sudah memberikan kesempatan dan pembiayaan untuk penelitian ini. Peneliti juga mengucapkan terimakasih kepada semua pihak yang telah membantu penelitian ini.

\section{DAFTAR PUSTAKA}

Ardiyanti. 2016. Aplikasi Model Rasch pada Pengembangan Skala Efikasi Diri dalam Pengambilan Keputusan Karier Siswa. Jurnal Psikologi, Volume 43, Nomor 3, 2016: 248-263.

Aziri, Brikend. 2011. Job Satisfaction: A Literature Review. Management Research And Practice Vol. 3 Issue 4: 77-86

Bandura, A. 1994. Self Efficacy. In V.S. Ramachaudran (Ed.), Encyclopedia of human behavior (Vol. 4, pp. 71-81). New York: Academic Press. (Reprinted in H. Friedman (Ed), Encyclopedia of mental health. San Diego: Academic Press, 1998).

Boonzaier, B., Ficker, B., \& Rust, B. 2001. A review of research on the job characteristics model and the attendant Job Diagnostic Survey. South Africa Journal of Business and Management, 32: 11-34.

Champoux, J. E. 1980. A three sample test of some extensions to the job characteristics model of work motivation. Academy of Management Journal, 23: 466-478.

Cooper. D. R., Schindler, P. S. .2006. Business Research Methods. New York: McGrawHill. 
Gagne et al. 2014. The Multidimensional Work Motivation Scale: Validation Evidence In Seven Languages and Nine Countries. European Journal of Work and Organizational Psychology.

Ghozali, Imam. 2016. Aplikasi Analisis Multivariate dengan Program IBM SPSS 23. Semarang: Badan Penerbit Universitas Diponegoro.

Ghozali, Imam. 2014. Model Persamaan Struktural: Konsep dan Aplikasi dengan Program AMOS 22.0. Update Bayesian SEM. Semarang: Badan Penerbit Universitas Diponegoro.

Gibson, J. L., Ivancevich, J. M., Donelly, J. H., \& Konopaske, R. 2003. Organizations: Behavior, Structure, Processes. New York: McGraw Hill.

Hackman, J. R. Oldham G. R., Janson, R., \& Purdy K. 1975. New strategy for job enrichment. California Management Review, 17: 57-72.

Hair, J. F., Black, W. C., Babin, B. J., Anderson, R. E. 2014. Multivariate Data Analysis. London: Pearson.

Idaszak, J. R., \& Drasgow, F. 1987. A revision of the Job Diagnostic Survey: Elimination of a measurement artifact. Journal of Applied Psychology, 72: 69-74.

Judge, T.A., Erez, A., Bono, J.E., Thoresen, C.J. 2002. Are Measures of Self-Esteem, Neuroticism, Locus of Control, and Generalized Self-Efficacy Indicators of a Common Core Construct? Journal of Personality and Social Psychology, 83(3): 693710.

Juniari, N. K. E, Riana I. G., \& Subudi, M. 2015. Pengaruh Motivasi terhadap Kepuasan Kerja dan Kinerja Pegawai Negeri Sipil (PNS) di Sekolah Tinggi Pariwisata Nusa Dua Bali. E-Jurnal Ekonomi dan Bisnis Universitas Udayana 4.11: 823-840.

Kurnia, A. M., Sunuharyo B. S., Utami H. N. Pengaruh Motivasi Kerja Terhadap Kepuasan Kerja Dan Prestasi Kerja Karyawan (Studi Pada Karyawan Pt. Askes (Persero), Cabang Boyolali).

Lodjo, Fernando S. 2013. Pengaruh Pelatihan, Pemberdayaan dan Efikasi Diri terhadap Kepuasan Kerja. Jurnal EMBA Vol.1 No.3 Juni 2013, Hal. 747-755.

Luszczynska, A., \& Schwarzer, U.C.R. 2005. The General Self-Efficacy Scale: Multicultural Validation Studies. The Journal of Psychology, 139(5): 439-457.

Narendra, G. 2017. Pengaruh Efikasi Diri Terhadap Kepuasan Kerja Dengan Motivasi Sebagai Variabel Intervening Pada PDAM Surya Sembada Kota Surabaya. Jurnal Ilmu Manajemen Volume 5 Nomor 3- Jurusan Manajemen Fakultas Ekonomi Universitas Negeri Surabaya.

Neuman, W. Lawrence. 2006. Social Research Methods (Qualitative and Quantitative Approaches). Pearson Education, Inc. United States of America.

Oldham, G. R., \& Hackman, J.R. 1981. Relationships between organizational structure and employee reactions: Comparing alternative frameworks. Administrative Science Quarterly, 26: 66-83.

Piccolo, R. F., \& Colquitt, J. A. 2006. Transformational leadership and job behaviors: The mediating role of core job characteristics. Academy of Management Journal, 49: 327340.

Purvanova, R. K., Bono, J. E., \& Dzieweczynski, J. 2006. Transformational leadership, job characteristics, and organizational citizenship performance. Human Performance, 19: $1-22$.

Robbins, S. P., \& Judge, T. A. 2016. Essentials of Organizational Behavior. USA: Pearson.

Saavedra, R. \& Kwun S. K. 2000. Affective states in job characteristics theory. Journal of Organizational Behavior, 21: 131-146. 
Sekaran, U. \& Bougie, R. 2016. Research Methods for Business. UK: John Wiley and Son. Schwarzer, R., \& Jerusalem, M. (1995). Generalized Self-Efficacy scale. In J. Weinman, S. Wright, \& M. Johnston, Measures in health psychology: A user's portfolio. Causal and control beliefs (pp. 35-37). Windsor, UK: NFER-NELSON.

Spector, P. E. 1997. Job Satisfaction: Application, Assessment, Cause and Consequences. London: Sage Publication.

Subyantoro, A. 2009. Karakteristik Individu, Karakteristik Pekerjaan, Karakteristik Organisasi dan Kepuasan Kerja Pengurus yang Dimediasi oleh Motivasi Kerja (Studi pada Pengurus KUD di Kabupaten Sleman). Jurnal Manajemen Dan Kewirausahaan, Vol.11, No. 1, Maret: 11-19.

Suyasa, P. T. Y. S. 2007. Job Satisfaction Measurement: The Alternative Method. Biennial International Conference On I/O Psychology: 477-485.

Williams, L. J., \& Anderson, S. E. 1991. Job satisfaction and organizational commitment as predictors of organizational citizenship behaviors. Journal of Management, 17: 601-617. 